\title{
Impact of Defoliation Intensity on Net Primary Productivity of Zoysia japonica-dominated Pasture under Grazing Conditions
}

\author{
Koji NAKAGAMI ${ }^{1,2}$, Seiichi SAKANOUE ${ }^{1,3}$ and Shigeo TAKAHASHI ${ }^{1 *}$ \\ ${ }^{1}$ Nasu Research Station, National Institute of Livestock and Grassland Science, National Agriculture \\ and Food Research Organization (NARO) (Nasushiobara, Tochigi 329-2793, Japan)
}

\begin{abstract}
Zoysia japonica Steud. is unique among Japanese native grasses due to its adaptation for grazing and has been re-evaluated by smallholders of beef calf production in Japan, because of its sustainability without any fertilizer. The relationship between stocking density and herbage production is a key factor for the sustainable management of grazing pastures. Moreover, net primary productivity including both above- and below-ground parts is a parameter used to quantify the net carbon absorption rate by living plants. Generally, stocking density levels affect plant production of pastures. Therefore, to determine the impact of defoliation intensity on net primary productivity of a Z. japonica-dominated pasture, the plant mass including below-ground parts was determined for three years under the stocking densities averaging 3.9, 2.7 and 1.6 animal units $\mathrm{ha}^{-1} \mathrm{y}^{-1}$ at the start of the grazing season under set-grazing of beef cattle from June to September. The net primary productivity ranged from 291 to $421 \mathrm{~g} \mathrm{DM} \mathrm{m}^{-2} \mathrm{y}^{-1}$ for above-ground (ANPP) and from -38 to $51 \mathrm{~g} \mathrm{DM} \mathrm{m}^{-2} \mathrm{y}^{-1}$ for below-ground parts. The ANPP was found to be affected by defoliation intensity, defined as the ratio of ANPP that was grazed, and attained a maximum when the defoliation intensity was about $40 \%$. As for cattle performance, they maintained their weight during the grazing season below $35 \%$ of annual defoliation intensity.

Discipline: Grassland

Additional key words: above-ground, animal unit, below-ground
\end{abstract}

\section{Introduction}

Zoysia japonica Steud. is a warm-season grass that can spread by both rhizome and stolon elongation, and is unique among Japanese native grasses due to its adaptation for grazing. Before the 1960's Z. japonica-dominated pastures were grazed by cattle, which were used for traction in agriculture, because these pastures can be sustained without any fertilizer. However, the purpose of raising cattle shifted to beef production when mechanization began to dominate agriculture. Hence, most of the $Z$. japonica-dominated pastures had been replaced with improved herbage species for enhancing livestock productivity. Currently in Japan, grazing on Z. japonicadominated pasture has been revived by smallholders for beef calf production because it is a low input and sustainable production system.

Among the studies on relationships between herbage and grazing animals, the topics of interest have been herbage production related to animal number grazed. Stocking density, which is defined as the number of animals per unit area of land, is the primary factor in grazing management. As for herbage production, net primary production (NPP) including both above- and below-ground plant parts is a parameter used to quantify the net carbon absorption rate by living plants because it is an important component of the biosphere carbon cycle in aspects of global climate change studies. Above-ground net primary production (ANPP) is directly related to the grazing capacity of grasslands. Most of the studies on Z. japonica-dominated pastures ${ }^{3-5,8,10}$ were concerned with the herbage pro-

\footnotetext{
Present address:

${ }^{2}$ Mountainous Grassland Farming Research Team, Miyota Research Station, National Institute of Livestock and Grassland Science, NARO (Miyota, Nagano 389-0201, Japan)

${ }^{3}$ Intensive Grazing Research Team, National Agricultural Research Center for Hokkaido Region, NARO

(Sapporo, Hokkaido 062-8555, Japan)

*Corresponding author: e-mail taka@affrc.go.jp

Received 3 September 2007; accepted 6 December 2007.
} 
duction, cattle productivity and nutrient content. However studies on the NPP have scarcely been conducted. This study was aimed at clarification of the NPP of Z. japonica-dominated pasture under different stocking densities and analysis of the variations in NPP in relation to defoliation intensity, which was defined as the ratio of ANPP that was grazed.

\section{Materials and methods}

\section{Study site}

The study site is located in the Fujinita ecological experimental pasture, Nasu Research Station, in the National Institute of Livestock and Grassland Science (139 $58^{\prime}$ E, 36 $55^{\prime} \mathrm{N}, 303-310 \mathrm{~m}$ altitude). Beef cattle have been grazed on this pasture since 1974 . The pasture was not treated with any chemical fertilizer throughout the experiment years. In 1995, three 1-ha experimental plots were established and assigned three different stocking densities. Japanese Black cattle were set-stocked on these plots during the 1995 to 2001 grazing seasons. Similar stocking densities were assigned to corresponding plots throughout the study. At the commencement of this grazing experiment, some parts of the field were covered with tall grasses such as silvergrass (Miscanthus sinensis Anderss.) and broomsedge (Andropogon virginicus L.) due to different experimental histories, but the vegetation was dominated by Z. japonica by the end of 1998 .
Therefore, the analysis was performed for data gathered in three years between 1999 and 2001.

\section{Climate conditions}

This area receives a lot of precipitation, except in winter. The annual total precipitation during the experimental years was $1,440-1,790 \mathrm{~mm}, 70 \%$ of which was recorded during the growing season of $Z$. japonica, from May to September. The monthly minimum and maximum air temperatures in the experimental years were -0.2 to $1.4^{\circ} \mathrm{C}$ in January or February and 24 to $25^{\circ} \mathrm{C}$ in July or August. Mean annual air temperature was $12^{\circ} \mathrm{C}$. The incoming solar radiation was around 4,500 $\mathrm{MJ} \mathrm{m}^{-2} \mathrm{y}^{-1}$, half of which was received in the growing season. The summers are hot and wet, and the winters are cold and dry. The meteorological condition was recorded by an automatic weather station at the Institute, located $3 \mathrm{~km}$ from the experimental site (Table 1).

\section{Grazing treatments}

The grazing treatments from 1999 to 2001 are shown in Table 2. Two, three and four heads of adult Japanese Black cattle were grazed under set-stocking for L, M and $\mathrm{H}$ plots, respectively. However, individual body weights ranged from 335 to $708 \mathrm{~kg}$ over the experimental years. The stocking density [animal unit (AU) ha ${ }^{-1}$ ] for the three plots were 3.5-4.6 (H), 2.3-3.0 (M) and 1.4-1.8 (L) at the start of the grazing season. Stocking densities were calcu-

Table 1. Monthly air temperature averages, precipitation total and solar radiation total at experimental field

\begin{tabular}{|c|c|c|c|c|c|c|c|c|c|}
\hline \multirow[t]{2}{*}{ Month } & \multicolumn{3}{|c|}{ Air temperature $\left({ }^{\circ} \mathrm{C}\right)$} & \multicolumn{3}{|c|}{ Precipitation (mm) } & \multicolumn{3}{|c|}{ Solar radiation $\left(\mathrm{MJ} \mathrm{m}^{-2}\right)$} \\
\hline & 1999 & 2000 & 2001 & 1999 & 2000 & 2001 & 1999 & 2000 & 2001 \\
\hline April & 10.7 & 9.7 & 10.8 & 126 & 211 & 16 & 425 & 482 & 540 \\
\hline May & 15.6 & 15.9 & 15.9 & 138 & 154 & 155 & 562 & 530 & 505 \\
\hline June & 19.4 & 19.6 & 19.4 & 288 & 147 & 154 & 446 & 435 & 427 \\
\hline July & 22.9 & 23.8 & 24.4 & 416 & 422 & 97 & 438 & 500 & 570 \\
\hline August & 24.9 & 24.5 & 22.3 & 320 & 88 & 364 & 429 & 491 & 357 \\
\hline September & 22.0 & 21.0 & 19.2 & 226 & 439 & 233 & 322 & 331 & 341 \\
\hline Annual mean or Total & 12.7 & 12.3 & 11.9 & 1,791 & 1,807 & 1,438 & 4,463 & 4,653 & 4,568 \\
\hline
\end{tabular}

Table 2. Stocking density at start of grazing season of each year

\begin{tabular}{|c|c|c|c|c|c|}
\hline \multirow[t]{2}{*}{ Year } & \multicolumn{3}{|c|}{$\begin{array}{l}\text { Stocking density } \\
\qquad\left(\mathrm{AU} \mathrm{ha}^{-1}\right)\end{array}$} & \multirow[t]{2}{*}{ Grazing period } & \multirow[t]{2}{*}{$\begin{array}{c}\text { Total of grazing } \\
\text { days }\end{array}$} \\
\hline & $\mathrm{H}$ & M & $\mathrm{L}$ & & \\
\hline 1999 & 3.5 & 2.7 & 1.8 & 11 June-30 July, 20 Aug.-23 Sept. & 83 \\
\hline 2000 & 3.7 & 2.3 & 1.5 & 9 June-18 July, 11 Aug.-22 Sept. & 81 \\
\hline 2001 & 4.6 & 3.0 & 1.4 & 7 June-27 July, 20 Aug.-17 Sept. & 78 \\
\hline Mean & 3.9 & 2.7 & 1.6 & & 81 \\
\hline
\end{tabular}


lated according to the equivalent to body weight of $500 \mathrm{~kg}$ head $^{-1}$. The stocking densities imposed in this experiment were relatively higher than those commonly seen in pastures of smallholder livestock keepers in rural conditions, because we attempted to clarify the possibility of sward degradation under high stocking density conditions. Cattle were introduced in early June and grazed till midSeptember. However, in the summer periods (for about 20 days) the pasture was rested from grazing due to shortage of herbage mass, during which cattle were raised on other similar Z. japonica-dominated pastures. Cattle were supplemented only by salt during the grazing period, and they were weighed every three weeks during the grazing period.

\section{Sampling and processing methods}

On each plot, six movable protection cages were set to measure the growth and residual of herbage, and the herbage consumed by the grazing cows. A quadrate (1.0 $\mathrm{m} \times 0.5 \mathrm{~m}$ ) was used for vegetation sampling. Samples were taken at 3 -week intervals by clipping the herbage in the quadrate to the ground level, both inside and outside of the movable cages. After herbage was clipped, soil surface litter was collected. To measure below-ground biomass (stolon-rhizome rooting system), six soil blocks $(25 \mathrm{~cm} \times 25 \mathrm{~cm}$ in ca. $15 \mathrm{~cm}$ depth) were taken from areas outside of cages in each plot followed by the collection of above-ground plant materials. The cages were then moved to a new area for successive sampling. The clipped samples of above-ground materials were sorted into dead herbage, live Z. japonica, and other plant species, the latter of which were lumped into a miscellaneous component; however bracken (Pteridium aquilinum L. Kuhn) was discarded. Soil blocks were washed in water and below-ground materials were collected on a sieve. Although some of the bracken and other plants were included in below-ground samples, they were excluded from the analysis. Below-ground live parts of Z.japonica, composing stolon or rhizome attaching roots, were separated by hand from the dead parts based on their elasticity and color properties. Live materials were lighter in color and more elastic than dead materials. All plant samples were oven-dried at $70^{\circ} \mathrm{C}$ for $48 \mathrm{~h}$ and weighed. Then resulting biomass was converted to $\mathrm{g} \mathrm{DM} \mathrm{m}^{-2}$ units.

\section{Calculations}

The above-ground consumption by cattle was calculated by the difference in plant materials between inside and outside of the cages. ANPP was calculated based on the differences in plant materials measured outside the cages at the current sampling time and inside the cages at the successive sampling time over a grazing season, i.e.,
ANPP $=\sum$ [difference in AGbiomass + difference in AGTotdead + (decomposition of dead materials)], where AGbiomass is above-ground live biomass, and AGTotdead is the above-ground standing dead materials including soil-surface litter. The estimation of dead materials that disappeared by decomposition during the sampling interval was calculated using the equation by Weigert and Evans $^{15}$, i.e., (ARr $\times$ AGTdead), where ARr is the aboveground relative rate of decomposition, and AGTdead is the mean amount of dead matter including soil surface litter in a sampling interval. The same equation was applied to calculate below-ground net primary production (BNPP), but the differences in plant materials were measured only on the outside of the cages. NPP is the sum of ANPP and $\mathrm{BNPP}$, and their units are $\mathrm{g} \mathrm{DM} \mathrm{m} \mathrm{m}^{-2} \mathrm{y}^{-1}$.

To calculate annual average of plant mass for aboveand below-ground parts throughout experimental years, the data which were taken at similar seasons were used. For the above-ground parts (Zoysia japonica live parts, total live parts including other plant species and dead plant parts), a sample size of four was selected from data taken on grazed area; late June or early July, late July, early and late September, but in 2001 it was three sampling times. For below-ground parts (Zoysia japonica live parts and its dead parts), sample size was three every year; early June, late July or August, and October or early November.

The decomposition rate of dead materials was determined using the litter-bag method ${ }^{14}$. Bags containing above-ground dead matter were placed on the ground surface, and those containing below-ground matter were buried in the soil at about $5 \mathrm{~cm}$ depth. Thereafter, six bags were taken every one month and the loss of material weight was determined to calculate the relative decomposition rate for above- and below-ground parts, respectively. The duration of the measurement was from July 2000 to October 2001. Soil temperature at $10 \mathrm{~cm}$ soil depth during growing seasons of two years varied from 9.0 (minimum in April in 2001) to $25.2^{\circ} \mathrm{C}$ (maximum in July in 2001), which was measured at the weather station. The growing season averages of decomposition rate observed during two years were $0.0023 \mathrm{~g} \mathrm{~g}^{-1}$ day $^{-1}$ and $0.0014 \mathrm{~g} \mathrm{~g}^{-1} \mathrm{day}^{-1}$ for above-ground and below-ground plant materials, respectively.

To determine the grazing impact on the primary productions (ANPP, BNPP and NPP), the defoliation intensity was considered instead of stocking density, because the level of stocking density did not seem to explain the impact on primary production. Usually defoliation intensity is defined as the ratio of herbage accumulation that is consumed (e.g., Bryan et al. ${ }^{2}$ ). We redefined it as the ratio of ANPP that is consumed during the grazing season 
instead.

\section{Data analysis}

Analysis of variance (ANOVA) was used to clarify the effect of treatment (stocking density level expressed as AU) and year on the plant (live and dead) mass present and the primary production (ANPP, BNPP and NPP). The General Linear Model (GLM) procedure was used as a two-way factorial ANOVA with no-replication. Here, the treatment was a fixed factor and year was also treated as a fixed factor. The relationship between stocking density level and defoliation intensity was analyzed using a piecewise linear regression model ${ }^{7}$. Also, the relationship between defoliation intensity and primary production was analyzed using a quadratic or linear regression model. All data were analyzed using SAS (version 9.1), by the Scientific Computing System at the Ministry of Agriculture, Forestry and Fisheries Network, Japan.

\section{Results}

\section{Plant mass present}

Seasonal averages of plant mass, which were calculated on the data obtained on the outside of the cages, are shown in Table 3. The vegetation was dominated by $Z$. japonica, which comprised $84-94 \%$ of above-ground live biomass. However, its percentage in L plot was relatively lower than those in the other plots. The averages of above-ground parts ranged from $77(\mathrm{H})$ to $128(\mathrm{~L}) \mathrm{g} \mathrm{m}^{-2}$ for live mass and from $123(\mathrm{H})$ to $171(\mathrm{~L}) \mathrm{g} \mathrm{m}^{-2}$ for dead mass. Both live mass and dead mass present were affected by the stocking density. According to ANOVA, the stocking density had a significant impact on the total live mass $(p<0.01)$ and on the dead mass $(p<0.05)$. Also year had a significant effect on total live plant mass; the lowest live mass for all plots was recorded in 1999 ( $\mathrm{p}<0.01)$, which might be due to the low sunshine from spring to summer in that year. The average dead mass was about 1.3-1.6 times of above-ground total live plant mass.

The averages of total below-ground plant parts including dead material ranged from 242 to $403 \mathrm{~g} \mathrm{~m}^{-2}$. The stocking density had no effect on the below-ground live mass, but had an effect on the dead mass $(\mathrm{p}<0.01)$; those weights increased with increases in stocking density levels. It was observed that the below-ground plant materials had a tendency to increase over the three years in all the plots, which might compensate for the reduction of below-ground materials in 1999. There was a reduction of $6-17 \%$ in the below-ground live mass in 1999, as compared to that in 1998, when they were recorded to be 289 for $\mathrm{H}, 242$ for $\mathrm{M}$ and $226 \mathrm{~g} \mathrm{~m}^{-2}$ for L plots. The reason for the reduction shown in 1999 was not clear, but a flood caused by heavy rainfall in August 1998 might have damaged below-ground organs. Below-ground dead mass was around $10-20 \%$ of the total below-ground plant materials on average over all years.

\section{Net primary productivity}

ANPP and BNPP observed in this experiment are shown in Table 4. The average values $\left(\mathrm{g} \mathrm{m}^{-2} \mathrm{y}^{-1}\right)$ of ANPP were 365 for H, 355 for M, and 382 for L plots over the experiment years. There was not a significant effect of stocking density on the ANPP, while significant differences in its amount were detected among the years; it was the lowest in $1999(\mathrm{p}<0.05)$. The average of BNPP for all treatments over years was $18 \mathrm{~g} \mathrm{~m}^{-2} \mathrm{y}^{-1}$, and there were no significant differences among treatments or years. In some cases, negative values were calculated ( $\mathrm{H}$ plot in 2000 and $\mathrm{M}$ plot in 2001). Because the BNPP accounted for only a small portion (3-6\%) of NPP, NPP showed similar performance with ANPP, but there were no significant differences among treatments.

Table 3. Seasonal averages of plant mass measured during grazing season $\left(\mathrm{g} \mathrm{DM} \mathrm{m}^{-2}\right)$

\begin{tabular}{|c|c|c|c|c|c|c|c|c|c|c|c|c|c|c|c|c|c|c|}
\hline \multirow[t]{3}{*}{ Year } & \multicolumn{12}{|c|}{ Above-ground ${ }^{\text {a) }}$} & \multicolumn{6}{|c|}{ Below-ground $^{\text {b) }}$} \\
\hline & \multicolumn{4}{|c|}{$\mathrm{H}$} & \multicolumn{4}{|c|}{ M } & \multicolumn{4}{|c|}{$\mathrm{L}$} & \multicolumn{2}{|c|}{$\mathrm{H}$} & \multicolumn{2}{|c|}{ M } & \multicolumn{2}{|c|}{$\mathrm{L}$} \\
\hline & $\mathrm{Z}$ & $\mathrm{O}$ & T-live & Dead & $\mathrm{Z}$ & $\mathrm{O}$ & T-live & Dead & $\mathrm{Z}$ & $\mathrm{O}$ & T-live & Dead & Live & Dead & Live & Dead & Live & Dead \\
\hline 1999 & 44 & 5 & 49 & 95 & 48 & 4 & 52 & 118 & 67 & 13 & 80 & 169 & 240 & 58 & 215 & 42 & 213 & 29 \\
\hline 2000 & 88 & 4 & 92 & 105 & 94 & 4 & 98 & 115 & 127 & 15 & 142 & 150 & 303 & 64 & 329 & 44 & 300 & 38 \\
\hline 2001 & 86 & 4 & 90 & 169 & 96 & 5 & 101 & 172 & 138 & 24 & 162 & 195 & 348 & 52 & 361 & 42 & 330 & 32 \\
\hline mean & 73 & 4 & 77 & 123 & 79 & 4 & 83 & 135 & 111 & 17 & 128 & 171 & 297 & 58 & 302 & 43 & 281 & 33 \\
\hline
\end{tabular}

a): Z; Zoysia japonica live mass, O; other species live mass, T-live; Z+O, Dead; dead materials including soil surface litter. Sample size in each year was 4, but 3 in 2001.

b): Live; Zoysia japonica live mass, Dead; Zoysia japonica dead mass. Each is constituted of stolon-rhizome attaching roots. Sample size in each year was 3 . 
Table 4. Primary production under different stocking density

\begin{tabular}{lcccc}
\hline \multirow{2}{*}{ Year } & & \multicolumn{3}{c}{ Primary production $\left(\mathrm{g} \mathrm{DM} \mathrm{m}^{-2} \mathrm{y}^{-1}\right)$} \\
\cline { 3 - 5 } & & ANPP & BNPP & NPP \\
\hline \multirow{2}{*}{1999} & $\mathrm{H}$ & 317 & 13 & 330 \\
& $\mathrm{M}$ & 291 & 51 & 342 \\
& $\mathrm{~L}$ & 374 & 37 & 411 \\
2000 & $\mathrm{H}$ & 410 & -16 & 395 \\
& $\mathrm{M}$ & 421 & 47 & 468 \\
& $\mathrm{~L}$ & 407 & 21 & 428 \\
2001 & $\mathrm{H}$ & 368 & 18 & 385 \\
& $\mathrm{M}$ & 352 & -38 & 315 \\
& $\mathrm{~L}$ & 364 & 25 & 389 \\
Mean & $\mathrm{H}$ & 365 & 5 & 370 \\
& $\mathrm{M}$ & 355 & 20 & 375 \\
& $\mathrm{~L}$ & 382 & 28 & 409 \\
\hline
\end{tabular}

\section{Relationships between stocking density and defoliation intensity}

The defoliation intensity showed a linear increase from 30 to $60 \%$ with increases in stocking density from 1.4 to $2.0 \mathrm{AU} \mathrm{ha}^{-1}$, but reached a plateau of around $60 \%$ beyond 2.0 $\mathrm{AU} \mathrm{ha}^{-1}$ (Fig. 1). Two regression lines by the piecewise regression model intersected at $2.0 \mathrm{AU} \mathrm{ha}^{-1}$ of stocking density $(\mathrm{y}=-29.4+42.6 \mathrm{x}$ for $1.4<\mathrm{x} \leq 2.0$ and $\mathrm{y}=56.3+0.51 \mathrm{x}$ for $2.0<\mathrm{x}<4.6$, where $\mathrm{x}=$ stocking density and $\mathrm{y}=$ defoliation intensity; $\mathrm{R}^{2}=0.877$ ).

\section{Relationship between defoliation intensity and NPP}

Figure 2 shows a quadratic regression of the ANPP on defoliation intensity, which indicated that the production attained a maximum at a defoliation intensity of $43 \%$ $\left(\mathrm{R}^{2}=0.671\right.$; both quadratic and linear term, $\left.\mathrm{p}<0.05\right)$. For the BNPP, the linear regression on defoliation intensity was applied, but it did not show a significant relationship due to greater variation in the estimations of BNPP. The same regression applied for NPP as for ANPP showed that both parameters of quadratic and linear terms were not significant. Since the NPP is the sum of ANPP and BNPP, the relationship of NPP with defoliation intensity was confused by disordered variation in BNNP.

\section{Cattle body weight changes}

Because the study was not conducted from the viewpoint of cattle production, most of the individual cattle lost weight during grazing. The weight changes for each treatment during the grazing season were calculated over years. The treatment averages of weight change among experimental years are shown in Fig. 3, which showed that the body weight was maintained when the defoliation

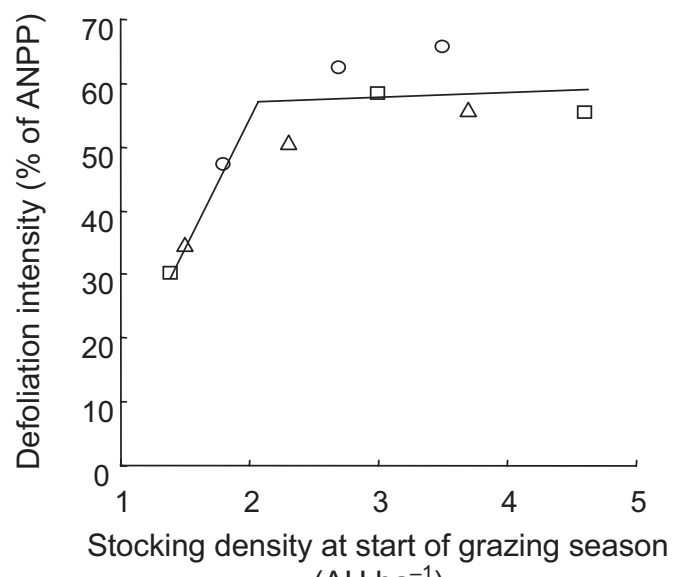

$\left(\mathrm{AU} \mathrm{ha}^{-1}\right.$ )

Fig. 1. Relationship between stocking density and defoliation intensity

Symbols in figure represent the years observed; $\bigcirc: 1999, \triangle: 2000, \square: 2001$.

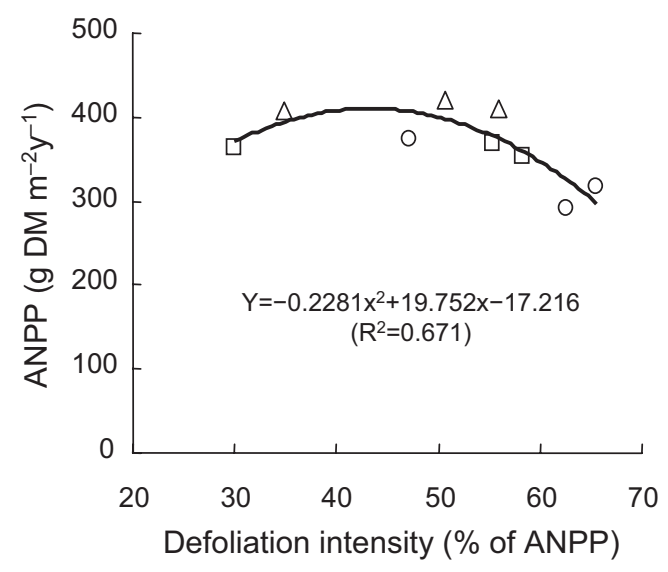

Fig. 2. Effect of defoliation intensity on ANPP

Symbols in figure represent the years observed; $\bigcirc: 1999, \triangle: 2000, \square: 2001$.

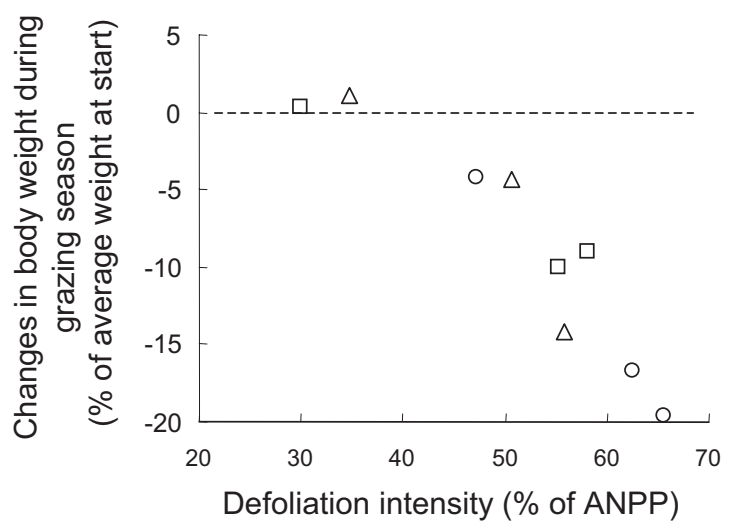

Fig. 3. Cattle weight changes affected with defoliation intensity

Symbols in figure represent the years observed; $\bigcirc: 1999, \triangle: 2000, \square: 2001$. 
intensity was below $35 \%$, while they lost weight greatly at higher defoliation intensity.

\section{Discussion}

$Z$. japonica grows well in hot climate conditions because it is a warm-season grass. ANPP of Z. japonicadominated grazing pasture in Shikoku ${ }^{10}$, an area southwest of our study site, is reported to be $570-750 \mathrm{~g} \mathrm{~m}^{-2} \mathrm{y}^{-1}$. This included other accompanying plant species, which were calculated as the summation of re-growth in aboveground live materials. Since the dead material accumulation and their decomposition were not considered in the calculation, those ANPP values would be under-estimated. However, it amounts to 2 times that observed in our pastures, because the climatic conditions in Shikoku are more suitable for Z. japonica than that in our area and also some chemical fertilizers were applied. Studies have seldom reported on the NPP measured on grazed native pasture in Japan, so we compared our results with that on the native grasslands of the US ${ }^{12}$. ANPP and BNPP in those grazing grasslands ranged from 54 to $523 \mathrm{~g} \mathrm{~m}^{-2} \mathrm{y}^{-1}$ and 57 to 1,019 $\mathrm{g} \mathrm{m}^{-2} \mathrm{y}^{-1}$, respectively. The productivity on temperate pastures occurring in the middle latitudes largely depends on the precipitation. In the regions such as the Bridger and Osage site in the US, where the annual precipitation is around $1,000 \mathrm{~mm}$, the ANPP ranged from 145 to $523 \mathrm{~g} \mathrm{~m}^{-}$ ${ }^{2} \mathrm{y}^{-1}$ and BNPP ranged from 421 to $983 \mathrm{~g} \mathrm{~m}^{-2} \mathrm{y}^{-1}$. Compared with those native grasslands observed in the US, the ANPP on our Z. japonica-dominated pasture was relatively lower. The extremely lower values of BNPP observed in the Z japonica-dominated pasture might be distinctive of plants with a stolon-rhizome rooting system. In the estimation of BNPP in our study, the negative values were calculated in some cases because of the great reduction in below-ground biomass during the sampling period. Since there was usually great variation in belowground plant mass, the negative values might be caused by sample variation when samples were measured under a small area $\left(0.25 \times 0.25 \mathrm{~m}^{-2} \times 6\right.$ plots in this study $)$.

Although herbage mass present was affected by the stocking density, there was not an impact on the NPP and ANPP. This indicates that the stocking density which is defined by animal heads grazed per land area is nominal and not directly related to primary production. According to the grazing optimization hypothesis ${ }^{6}$, the grazing at intermediate intensities stimulates plant production and enhances the primary production of grazed plants. The mechanisms for compensatory growth are generally considered on an increased nutrient availability through nutrient input by feces or urine, and a reduction of shading by taller neighbors or standing dead. Considering the prop- erties of $Z$. japonica which have evolved under grazing conditions it might have an optimal condition which attains maximal primary production. Therefore, to clarify the grazing impact on the primary production, the effect of defoliation intensity was considered as a more strict measurement instead of stocking density. The results showed that ANPP in our pasture attained a maximal value at about $40 \%$ of annual defoliation of ANPP. From Fig. 2 it seems that ANPP becomes a constant at lower defoliation intensity, but it is known that the production of $Z$. japonica-dominated pasture is depressed under un-grazed condition. The data was not presented precisely, but ANPP were from 195 to $227 \mathrm{~g} \mathrm{~m}^{-2}$ under conditions protected from grazing till mid-August in 1999. Since the following production measured under the grazing condition ranged from 50 to $78 \mathrm{~g} \mathrm{~m}^{-2}$, annual ANPP would be calculated to be around $300 \mathrm{~g} \mathrm{~m}^{-2}$ or less under un-grazing condition (i.e., defoliation intensity is zero).

From the studies conducted on the Great Plains in the US, herbaceous production was little affected by 20 years of differential stocking rates ${ }^{11}$, where the stocking rate $\left(\right.$ AUD ha ${ }^{-1}$ ) means animal units over a specific time period per unit area of land. In order to compare the results in the US with ours, the stocking density imposed in our experiment was converted to the stocking rate, based on the calculation by multiplying stocking density with the number of grazing days. In the US study the stocking rates were in the range of 40-90 AUD ha ${ }^{-1}$, much lower contrasted to that in our study (110-360 AUD ha $\left.{ }^{-1}\right)$. In the Kansas prairie, it is recommended that no more than $50 \%$ of the current season's growth be removed during the grazing season because plants must store reserves by leaving sufficient leaf area ${ }^{9}$. In comparison with the US prairie, $Z$. japonica-dominated pasture could be said to be tolerant to higher defoliation. High stocking density did not promote the degradation on Z. japonica-dominated pasture in consideration of ANNP on H plot. In 2001, when six years had passed since the plot had been introduced to heavy grazing, the production did not show a significant decrease compared with the L plot. However, because of the shortage in herbage present in the autumn, high stocking density lowered the cattle body weight. The animal body weight was maintained at less than $35 \%$ of defoliation intensity, while ANPP was maximized at slightly greater intensity, i.e., $42 \%$. From the viewpoint of animal production under set-grazing, defoliation intensity must be maintained at lower levels than that for the primary production to be maximized.

In the era of rapid economic growth in Japan, most of native grazing pastures were converted to pastures where improved temperate herbage species, such as timothy (Phleum pratense), orchardgrass (Dactylis glomerata L.) 
and tall fescue (Festuca arundinacea) were introduced. The herbage yield ${ }^{1}$ of improved pastures under proper fertilizer application is about $1,000 \mathrm{~g} \mathrm{~m}^{-2} \mathrm{y}^{-1}$, which amounts to about 3 times or more than that in the Z. japonica-dominated pastures in our study. However, several pastures have degraded because the cool-season perennial grasses poorly adapted to Japanese hot summer conditions. These days, grazing on a Z. japonica-dominated pasture has been revived by smallholder livestock keepers in rural areas where pastures had to be established on steep slopes or in paddy fields taken out of cultivation. Native herbage species adaptability to cattle grazing must be re-evaluated, when planning to improve the livestock productivity by replacing native pasture species with improved ones. The contribution of NPP to the global environmental problem was not discussed, but grazing on native pastures would be a sustainable system because the use of pasture without cultivation saves soil organic carbon ${ }^{13}$ and avoids fossil fuel consumption.

\section{Acknowledgments}

The authors thank Dr. Masae Shiyomi for his advice on statistical analysis and valuable comments.

\section{References}

1. Akiyama, T. et al. (1981) Ecological efficiencies of energy conversion in pasture V. Seasonal and annual changes of dry matter production in the grazing pasture. Bull. Natl. Grassl. Res. Inst., 20, 20-41 [In Japanese with English summary].

2. Bryan, W. B. et al. (2000) Productivity of Kentucky bluegrass pasture grazed at three heights and two intensities. Agron. J., 92, 30-35.

3. Hayasaka, K., Nishiguchi, Y. \& Ando, S. (2005) The productivity and nutritional management of breeding Japanese Black cows according to stocking rates on no-fertilized Zoysia-dominated grassland. Bull. Natl. Agric. Res. Cent. West. Reg., 4, 69-107 [In Japanese with English summary].
4. Hirayoshi, I. \& Matsumura, M. (1957) Studies on Zoysia range 1. Jpn. J. Grassl. Sci., 3, 16-22 [In Japanese with English summary].

5. Ishida, R. (1990) General remarks on the research works of Japanese lawn grass (Zoysia japonica STEUD.) and Zoysia type grasslands in Japan. Jpn. J. Grassl. Sci., 36, 210-217 [In Japanese with English summary].

6. MacNaughton, S. J. (1979) Grazing as an optimization process: grass-ungulate relationships in the Serengeti. Am. Nat., 113, 691-703.

7. Marsh, L., Maudgal, A. \& Raman, J. (1991) Alternative methods of estimating piecewise linear and higher order regression models using SAS software. SUGI, 15, 523-527.

8. Miyazaki, A., Kasagi, S. \& Mizuno, T. (1984) Digestibility of Zoysia-type grass by Japanese deer. Jpn. J. Zootech. Sci., 55, 661-669.

9. Ohlenbusch, P. D. \& Watson, S. (1994) Stocking rate and grazing management. Kansas State University Agricultural Experiment Station and Cooperative Extension Service, MF-1118. http://www.oznet.ksu.edu/.

10. Otsuki, K. et al. (1984) Studies on movement of Zoysiatype grassland 2. Succession of vegetation and grazing capacity of short grass type grassland under rotational grazing. Bull. Shikoku Natl. Agric. Exp. Stn., 44, 158-185 [In Japanese with English summary].

11. Robert, L. \& Sims, P. L. (2004) Stocking rate, precipitation, and herbage production on sand sagebrush-grassland. J. Range Manag., 57, 148-152.

12. Sims, P. L. \& Singh, J. S. (1978) The structure and function of ten western north American grasslands III. Net primary production, turnover and efficiencies of energy capture and water use. J. Ecol., 66, 573-597.

13. Takahashi, S. et al. (2007) Soil organic carbon storage in grazing pasture converted from forest on Andosol soil. Grassl. Sci., 53, 210-216.

14. Takahashi, S. et al. (2003) Plant and cattle production on Zoysia japonica field at Fujinita site. In Report on the grassland dynamics in Japan -The 6th report, eds. Kano et al. National Institute of Livestock and Grassland Science, Tochigi, Japan, 32-44 [In Japanese].

15. Weigert, R. G. \& Evans, F. C. (1964) Primary production and disappearance of dead vegetation on an old field in south eastern Michigan. Ecology, 45, 49-62. 